\title{
Review of Research Work on Performance Measures in Die Sinking EDM
}

Syed Asghar Husain Rizvi ${ }^{* 1}$, Prem Kumar Bharti ${ }^{2}$ and Sanjay Agarwal ${ }^{3}$

1.* Research Scholar, Deptt. of Mechanical Engineering, Integral University, Lucknow, (U.P.), India, e-mail : sahr.me@gmail.com

2. Professor \& Head, Deptt. of Mechanical Engineering, Integral University, Lucknow, (U.P.), India.

3. Professor, Deptt.of Mechanical Engineering, Bundelkhand Institute of Engineering and Technology, Jhansi, (U.P.), India.

\section{Publication Info}

Article history :

Received : 10 ${ }^{\text {th }}$ Aug., 2019

Accepted : 08 ${ }^{\text {th }}$ Dec., 2019

DOI : 10.18090/samriddhi.v11i02.8

Keywords: EDM, Electrical Parameters, Non-Electrical Parameters, Performance Measures

*Corresponding author :

Syed Asghar Husain Rizvi

e-mail : sahr.me@gmail.com

\begin{abstract}
Electro Discharge Machine (EDM) is one of the non-conventional machines utilized to cut hard material and complex contours that are difficult to achieve by other conventional techniques. The material is removed by spark generated between the tool and work gap, which melts and vaporizes the material and is then flushed along the flow of dielectric. It has been extensively used in various industries, for improved efficiency and productivity. The present research tends to review the diverse work executed by researchers on various performance measures of EDM. The utmost considered performance measures are material removal rate, tool wear rate, surface roughness, radial overcut, residual stress, white layer thickness and black layer that are reviewed in this paper. The paper also elaborates future trends for research on EDM.
\end{abstract}

\section{INTRODUCTION}

$\square$ lectro-discharge Machining or generally known as EDM is a non-conventional approach of material removal process that is extensively used to produce dies, moulds, etc in automotive and aerospace industries. This machining process is applicable for very hard materials that are difficult to cut by other conventional machining processes. It is utilized to cut complex contours and delicate cavities which are impossible to attain by other methods. A thorough review process has been conducted in order to understand the importance of research work on performance measures held related to EDM.

The review presented here is based on the research work performed on various performance measures in die sinking EDM viz. material removal rate (MRR), tool wear rate (TWR), surface roughness, radial overcut, residual stress, white layer formation on workpiece and black layer formation on tool. The review will present the current trend and the activities carried out in order to influence the performance measures of EDM. Based on the literature survey, the research gaps are identified and the objectives of research are found.

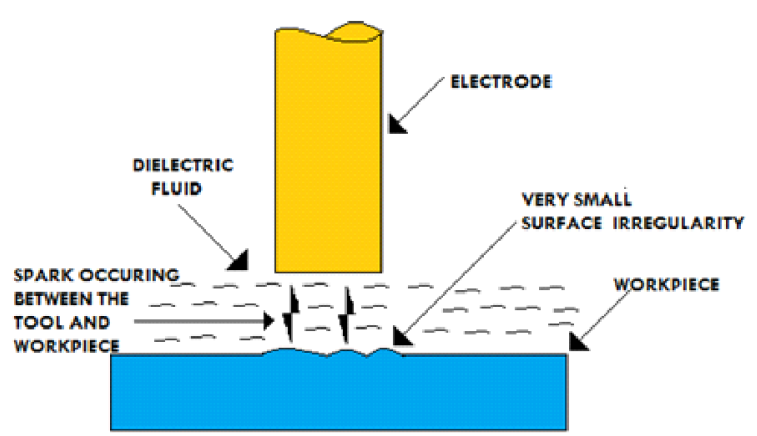

Fig.1: Spark occurrence at closest point of the work and the tool 


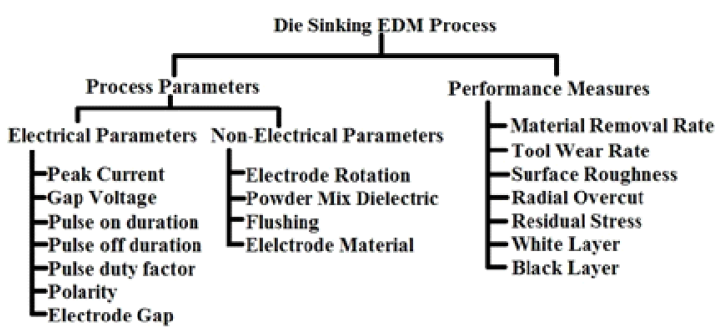

Fig.2: Process parameters and performance measures of die sinking EDM

\section{PERFORMANCE MEASURES}

\subsection{Material Removal Rate (MRR)}

In the literature survey, peak current (Ip) is discovered to be the crucial parameter while considering the material removal rate of the metals and the MRR increases with rise in the level of peak current $[3,10,11,18,25,30,34,36,43,45$, $57,49,52,60-62,64,65]$. More or less all the researchers have concentrated on peak current and have come to an inference that it has major influence on material removal rate. The peak current governs the intensity of sparks striking the workpiece and guides to utmost removal of work material. A maximal value of peak current will favor for achieving maximum material removal rate. More or less all the researchers have found that material removal rate follows an escalating trend with peak current.

The subsequent considered and influencing parameter found to govern the material removal rate of the work material is pulse on duration or pulse on time (Ton). It has also alike trend as perceived for peak current and the material removal rate increase with rise in the level of pulse on time [3, $10,11,18,25,31,34,37,43,52,61,62]$.

Considering pulse off time (Toff), it shows fluctuating effect on material removal rate $[3,36]$. Some researchers have also claimed that pulse off time have great dominance on material removal rate and it increases with rise in the level of pulse off time [13,52].
Another parameter that has gained notice during the past literature study is the voltage or gap voltage. Almost all the researchers have undertook voltage among their study parameters. The researcher proclaimed that voltage is the least determine parameter for material removal rate $[10,64,65]$. A couple of researchers also deduced that when the value of voltage is increased, the extent of material removal rate in decreased $[18,34,64,65]$.

In recent time, pulse duty factor $(\tau)$ has also been undertaken to determine EDM parameter considered by the researchers. It is perceived during the survey that elevated pulse duty factor yields greater material removal rate [24, 31, 37, 43, 49]. For preferable material removal rate, a elevated value of pulse duty factor is recommended by the researchers.

While undergoing the survey, it was found that the material removal rate is also affected by the electrode material used to machine the workpiece $[11,12,14,15,52]$. The researchers have claimed that using a copper electrode imparts better material removal rate in contrast to other materials [11,31]. Copper tungsten was also observed to have influence on material removal rate and yields more MRR [6]. Shape of the electrode used to machine the work also dominates the MRR. Round shaped electrode was found to be imparting higher MRR followed by square shaped electrode [51]. The MRR was also found to increase with higher tool rotation during EDM process [58].

The discharge energy has also influenced the enhancement of the material removal rate and the MRR rises with it $[5,64]$. More the discharge energy, more is the intensity of spark and hence better MRR is achieved.

Some of the authors have also considered fluid pressure of the dielectric medium to be a process 
parameter and concluded that keeping a lower level of it will result in higher material removal rate $[13,31,58]$. The flushing leads to removal of debris from the gap and medium for spark transmission. If optimum pressure is not maintained then the debris of the work material removed from the surface may get intact to the work material leading to interruption of sparks. When tap water was chosen over other dielectric fluids, an enhanced material removal rate were achieved [17,31]. Concentration of powder also influences the material removal rate that leads to its enhancement [47].

\subsection{Tool Wear Rate (TWR)}

One more common performance measure for focus in present researches on EDM is the Tool wear rate. The excess tool wear is considered to be a flaw of EDM process that has to be optimized to acquire perfect shape and long lasting use of tool.

The electrical parameters have crucial dominance on the tool wear rate [12] and their increase or decrease changes the tool wear drastically. The discharge energy of the spark considerably influences the tool wear with increase in the discharge energy and the tool wear rate rises [4,29,41,53].

Peak current has more pronounced effect on tool wear rate and the tool wear rate rises with elevation in the level of peak current $[4,7,29,34,41,48,62]$. Peak current exerts influence on the intensity of spark and at higher value of peak current, the spark intensity hikes. This will lead to more positive ions striking the surface of the tool and hence the tool wear rate shoots up with peak current.

Moreover, pulse on time has a similar impact on tool wear rate as that of the peak current. Researchers have discovered that larger pulse on time (Ton) results in higher tool wear rate and smaller pulse on time results in lower tool wear rate $[7,18,27,29,34,62]$. Few researchers have also concluded that tool wear rate reduces with rise in the level of pulse on time $[41,48]$. This might depend on the material of tool and work used in the study.

A mix result was interpreted for gap voltage with respect to tool wear rate. Though being a insignificant parameter for tool wear rate [18] but the tool wear rate increases with increase in the voltage [16]. Factors like pulse duty factor, voltage, pulse off time were discovered insignificant towards tool wear rate $[16,18,29,34,62]$.

Tool rotation was also considered by few researchers and it was found that increase in tool rotation will enhance the tool wear rate as the debris from the gap is instantly removed [63]. Considering all these, even then tool rotation is an insignificant parameter for tool wear rate [4,53]. Many of the researches have focused on tool material in their study and have concluded that the tool material also dominate the tool wear rate $[12,29,52,60]$. Majority of the researchers have used copper, brass, copper-tungsten, copperchromium, graphite tool in their study. Copper based tools are found to have low tool wear rate.

\subsection{Surface Roughness}

Better surface characteristics are majorly needed in present time industries. Research has been carried out to find the influence of various EDM parameters on the quality of surface produced post machining. Due to advancement of technology and demand, it is required to produce a finished product in one go of machining. Since EDM is a non-conventional precise machining process, hence it is required to produce a surface that does not require further finishing after machining on EDM. Several researches have 
performed to find optimum machining parameters to obtain best surface quality. All most all the researches were focused on surface quality of the machined work surface.

During the survey, it was found that peak current is one of the most remarkable EDM parameter that considerably influenced the quality of surface produced by machining. Surface roughness directly depends upon peak current $[8,11,16,18$, $25,28,46,54-56,69]$. Majority of the researchers have suggested a lower level of peak current in order to acquire better surface finish $[8,11,16$, $18,25,30,31,46,48,50,52,56,57,59,66]$. This might be due to the intensity of spark at higher level of current which will cause larger craters and hence produces a rough surface on machine work material.

Moving on to the second most commanding parameter spotted in various literature i.e. pulse on time or pulse on duration (Ton). It causes a uniform increase in surface roughness $[5,8,16$, $48,50]$. Surface roughness depends upon the on duration of the pulse. Various literatures have suggested that a lower pulse on time should be set to procure lower surface roughness $[8,16,18,25$, $36,44,46,48-50,52,57,59,62]$. This is similar to the trend followed by peak current.

Researchers have also quoted that the surface roughness directly depends upon the discharge energy [5,24-26,54,66]. It plays a vital role in the quality of surface produced while machining on EDM. Discharge energy of spark depends upon various parameters on the process.

Few literatures also quoted that the electrode material is the most significant non-electrical parameter for surface roughness [11,14]. Tools such as copper, brass, copper-tungsten, aluminium, graphite, etc were used in the researches to find the best suited electrode. Some of the reviews concluded that copper gives worst surface finish as compared to other electrode while machining stainless steel $[11,31]$ while for tools steel, copper produces best surface finish [14]. Titanium based alloy \& aluminium electrode prove to be better than graphite and copper [50]. Brass was also found to produce better surface finish [11]. Few researches also quoted that use of copper-tungsten electrode will deliver minimum surface roughness $[31,44]$.

Moving on the polarity of the tool, a mix review is obtained on it. Few literatures were found that were supporting the negative polarity of the tool for better surface finish [57] while others were in favor of positive polarity [30]. Polarity will influence the intensity of electrons striking the surface of the work material during machining on EDM.

Few researches have been performed with rotating tools and it was concluded by the researchers that surface finish in rotating tool is better than the traditional tool $[16,58]$. Pulse duty factor $[31,49,54]$ and gap voltage $[57,66]$ were observed to be the least influencing parameters for surface roughness. However a lower level of these parameters is suggested for better surface finish. Similarly tool shape is also observed to be insignificant for surface roughness [51], however the round shape produces smoother surface as compared to other shapes of the tool.

Researchers have also concluded that the powder mixed dielectric fluid also have major dominance on surface roughness and dielectric mixed with powder improves the surface finish as compared to the plain dielectric $[39,57,68]$.

Surface roughness is directly influenced by the hardness of the work materials [2]. Pulse off time was also observed by various researchers and was 
found to be insignificant for surface roughness as compared to other electrical parameters $[8,46,52]$.

\subsection{Radial Overcut (ROC)}

Many researches consider electrical parameters as major influencing parameters for ROC. Peak current is one those parameter that have major dominance on overcut of the machined hole [34$36,53,65]$ and it is suggested to keep a low value of Ip for lower ROC $[35,36]$. Voltage was also found to have mix influences. Some researches suggests it to be significant for overcut and a lower value is set to achieve lower overcut $[35,36]$ while the other recognize it as a least influencing parameter [65]. Higher the discharge energy, larger is the radial overcut $[36,53]$.

Pulse duty factor $(\tau)$ is also considered to have influence on radial overcut [34] while pulse on and off durations are insignificant for it [35]. With rotation speed of the electrode, the radial overcut is also increased [53].

Radial overcut also depends upon the tool material $[6,14]$. In a research, a $\mathrm{Cu}-\mathrm{W}$ tool offers lower ROC than copper electrode [6] while in other a copper tool offer a lower ROC than $\mathrm{ZrB2}-40$ wt \% $\mathrm{Cu}$ [14]. So tool material is an important aspect for ROC.

\subsection{Residual Stress}

Residual stresses are the internal stresses developed in the machined surface due to sudden cooling and phase change of the machined workpiece. Studies have been performed to analyze the development of residual stress either compressive or tensile. Majority of the researches have shown that only the thermal aspect is responsible for development of residual stress.

The tensile residual stress results from the rapid cooling and phase change occurring during the machining process $[23,32,42,63,64]$. The development of residual stresses results in crack formation on the machined surface $[19,23,32$, $38,42,63,64]$.

The review provide a mix views over the depth of these stresses developed. At one instance it is concluded that the residual stress increases rapidly with respect to depth and reaches a maximum value within the heat affected zone [20] while other conclude that it is generated near the surface and then fall rapidly with depth [21].

Fewer studies have shown the influence of electrical parameters on development of residual stress. Peak current was analyzed and found to have influence on residual stress and its value is increased with Ip $[61,64]$. Similarly pulse on time also directly influences the development of residual stress on the machined surface [61].

\subsection{White Layer Thickness}

In the review process, it was established that peak current and voltage have major dominance on white layer thickness over other electrical parameters. Higher current [9, 30, 33, 49, 50, 59] and higher voltage $[9,30,33,40,50]$ results in thicker white layer. White layer thickness also depends upon the discharge energy of the spark. Increase in discharge energy increases the recast layer thickness [5, 9, 26, 38, 48].

Pulse on time also has pronounced influence on white layer formation $[5,9,26]$. It should be kept lower to obtain minimum white layer thickness [30, 48, 49, 50, 59]. With increased in pulse duty factor $(\tau)$, the white layer thickness increases $[49,50]$. White layer formed is nonhomogenous and hence it experience cracks [22, 32].

Powder mixed dielectric reduces the formation of white layer [30, 33, 68]. A low powder concentration is suitable for lower white layer 
thickness [30, 33]. The material removal rate (MRR) is also found retarted by formation of white layer on machined surface [15]. Heat source parameter also have influence on formed recast layer $[5,26]$.

Recast layer thickness varies with respect to the drilling depth [19]. Researchers have also shown that negative polarity is suitable for lower white layer thickness [30]. Recast layer thickness reduces by rotary electrode as compared to stationary electrode [40]. The electrode material also has influence on white layer thickness [50].

\subsection{Black Layer}

During the process of sparking, a black layer or carbon layer is deposited on the tool surface that influences the effectiveness of the material removal process of EDM.

This black color developed on tool surface is due to the migration of carbon present in dielectric $[70,73,76]$. It changes the thermal conductivity of the tool [1]. This migration of elements from work and dielectric on the surface of tool transpire at extremely high temperature and this black layer fends off the tool wear [71].

The black layer does not constitute carbon alone, rather it also accommodates iron, chromium, vanadium and molybdenum [70,73]. The main inherent of the layer is carbon turn loose from the dielectric and the carbon layer with 15?20-?m extent linking rapidly to the top of tool at the initial phase. Furthermore, the order of carbon layer formation on the grounds of the temperature distribution theory of the electrode surfaces are discussed [72].

It is brittle in nature and affects the thermal conductivity of the tool [73]. The extent of black layer is conditional on the discharge energy [74]. Considering pulse duty factor, higher value assists black layer formation. No black layer was noticed at a lower magnitude of pulse duty factor [75].
This layer impedes the material removal from the workpiece [77]. The transmutation of the dielectric fluid lays the foundation of a thin film of carbon on the tool surface [78].

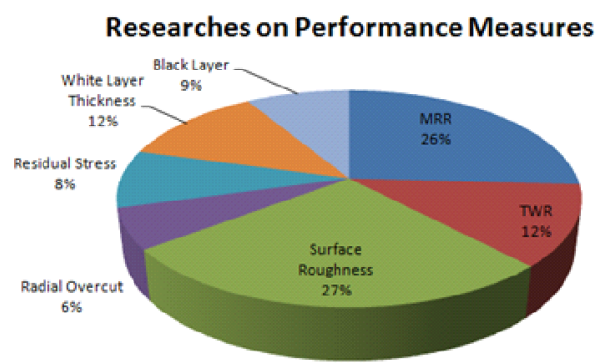

Fig.3: Researches on performance measures

\section{DISCUSSION AND FUTURE TRENDS}

After scrutinizing the diverse literature on performance measures of EDM, following conclusions have been derived:

Fig. 3 shows the percentage of researches conducted on various performance measures. It can be perceived that major work performed by researchers is on material removal rate and surface roughness. On the contrary, other considered performance measures are least studied.

- Few studies have been reported on radial overcut of machined hole. Major causes of radial overcut were not so effectively elaborated by the researchers.

- A very few literature were available on residual stress development in machined workpiece. However, no studies have been carried to express the influence of electrical parameters of EDM.

- There is no literature available on relation of residual stress with machined surface damage.

- Black layer formation on tool surface was studied by few researchers.

- Predominance of electrical parameters in observed in the literatures while the nonelectrical parameters have not received much focus. 
Syed Asghar Husain Rizvi, Prem Kumar Bharti and Sanjay Agarwal

\section{SUMMARY}

A review of the researches performed to assess the performance measure of EDM related to the electrical and non-electrical parameters have been presented through this paper. The review of past twenty years has been discussed. Each of the researchers have tried to enhance and optimize the performance measures of EDM with varying electrical and non-electrical parameters. Efforts were made by researchers to improve the performance of machining by combination of EDM parameters. Performance measures like MRR, TWR, surface roughness, radial overcut, residual stress, white layer thickness and black layer have been the cynosure of the researchers.

\section{ACKNOWLEDGEMENT}

The authors gratefully acknowledge Research and Development cell, Integral University, Lucknow for kind support and providing the Manuscript Communication Number (MCN) : IU/ R\&D/2019- MCN000667.

\section{REFERENCES}

[1] José Duarte Marafona "Black layer affects the thermal conductivity of the surface of copper-tungsten electrode" International Journal of Machine Tools and Manufacture, 2009, Vol. 42, pp. 482-488.

[2] Jose' Duarte Marafona, Arlindo Arau'jo "Influence of workpiece hardness on EDM performance" International Journal of Machine Tools and Manufacture, 2009, Vol. 49, pp. 744-748.

[3] M. M. Rahman, Md. Ashikur Rahman Khan, K. Kadirgama M. M. Noor and Rosli A. Bakar "Modeling of material removal on machining of Ti-6Al-4V through EDM using Copper Tungsten electrode and positive polarity" International Journal of Mechanical and Materials Engineering, 2010, pp. 135-140.

[4] M Gostimirovic, P Kovac, B Skoric \& M Sekulic "Effect of electrical pulse parameters on the machining performance in EDM" Indian Journal of Engineering \& Materials Sciences 2012, Vol. 18, pp. 411-415.

[5] Marin Gostimirovic, Pavel Kovac, Milenko Sekulic and Branko Skoric "Influence of discharge energy on machining characteristics in EDM" Journal of Mechanical Science and Technology 2012, Vol. 26, pp. 173-179.

[6] Subramanian Gopalakannan, Thiagarajan Senthilvelan "Effect of Electrode Materials on Electric Discharge Machining of 316 L and 17-4 PH Stainless Steels" Journal of Minerals and Materials Characterization and Engineering, 2012, Vol. 11, pp. 685-690.

[7] Joaquim Fonseca \& José Duarte Marafona "The effect of deionisation time on the electrical discharge machining performance" International Jornal of Advance Manufacturing Technology,2014, Vo. 71, pp. 471-481.

[8] Teepu Sultan, Anish Kumar, and Rahul Dev Gupta "Material Removal Rate, Electrode Wear Rate, and Surface Roughness Evaluation in Die Sinking EDM with Hollow Tool through Response Surface Methodology" International Journal of Manufacturing Engineering, 2014, pp. 1-14.

[9] J.F. Liu, Y.B. Guo "Modeling of White Layer Formation in Electric Discharge Machining (EDM) by Incorporating Massive Random Discharge Characteristics" 18th CIRP Conference on Electro Physical and Chemical Machining, 2016, Vo. 42, pp. 697-702.

[10] M.A. Ali, M. Samsul, N.I.S. Hussein, M. Rizal, R. Izamshah, M. Hadzley, M.S. Kasim, M.A. Sulaiman and S. Sivarao "The effect of EDM die-sinking parameters on Material Removal Rate of Beryllium Copper using full factorial method" Middle-East Journal of Scientific Research, 2013, Vol. 16, pp. 4450.

[11] Suraj Choudhary, Krishan Kant, Parveen Saini "Analysis of MRR and SR with different electrode for SS 316 on die-sinking EDM using Taguchi Technique" Global Journal of Researches in Engineering Mechanical and Mechanics Engineering, 2013, Vol. 13, pp. 14-21.

[12] Mehul Manoharan Abhi P. Valera Shrey M. Trivedi Kapil S Banker "Material Removal Rate, Tool Wear Rate and Surface Roughness Analysis of EDM Process" International Journal for Scientific Research \& Development, 2013, Vol. 1, pp. 407-409.

[13] Abhishek Gaikwad, Amit Tiwari, Amit Kumar, Dhananjay Singh "Effect of edm parameters in obtaining maximum MRR and minimum EWR by machining SS 316 using copper electrode" International 
Journal of Mechanical Engineering and Technology, 2014, Vol. 5, pp. 102-110.

[14] A.K. Khanra, B.R. Sarkar, B. Bhattacharya,L.C. Pathak, M.M. Godkhindi "Performance of ZrB2-Cu composite as an EDM electrode" Journal of Materials Processing Technology 2007, 183, pp. 122-126.

[15] B.V. Manoj Kumar, J. Ramkumar, Bikramjit Basu, S. Kang "Electro-discharge machining performance of TiCN-based cermets" International Journal of Refractory Metals \& Hard Materials, 2007, 25, pp. 293299.

[16] Saeed Daneshmand, Ehsan Farahmand Kahrizi, Ali Akbar Lotfi Neyestanak, Mehrdad Mortazavi Ghahi "Experimental Investigations into Electro Discharge Machining of NiTi Shape Memory Alloys using Rotational Tool” Int. J. Electrochem. Sci., 2013, Vol. 8, pp. 7484-7497.

[17] L. Tang \& Y. T. Du'Experimental study on green electrical discharge machining in tap water of Ti-6Al4Vand parameters optimization" International Journal of Advaced Manufacturing Technology, 2014, 70, pp. 469-475.

[18] Balbir Singh, Jatinder Kumar, and Sudhir Kumar "Investigating the influence of process parameters of ZNC EDM on machinability of A6061/10\% SiC composite" Advances in Materials Science and Engineering, 2013, pp. 1-8.

[19] Bülent Ekmekci, Atakan Sayar, T. Tecelli Öpöz and Abdulkadir Erden "Characteristics of surface damage in micro electric discharge machining of micro holes" Advanced Materials Research, 2010, Vols. 83-86, pp. 688-695.

[20] Bu“lent Ekmekci, Oktay Elkoca, A. Erman Tekkaya, Abdulkadir Erden "Residual stress state and hardness depth in electric discharge machining: De-ionized water as dielectric liquid" Machine Science and Technology, 2005, Vol. 9, pp. 39-61.

[21] Bülent Ekmekci, A. Erman Tekkaya, Abdulkadir Erden "Investigation Of Residual Stresses On Electrical Discharge Machined Surfaces" $6^{\text {th }}$ Biennial Conference on Engineering Systems Design and Analysis, 2002, pp. 1-6.

[22] Bu“Lent Ekmekci "White Layer Composition, Heat Treatment, and Crack Formation in Electric Discharge Machining Process" Metallurgical And Materials Transactions, 2009, Vol. 40B, pp. 7081.
[23] Bu“Lent Ekmekci and Yusuf Erso“Z "How suspended particles affect Surface morphology in powder mixed electrical discharge machining (PMEDM)", Metallurgical And Materials Transactions, 2012, Vol. 43B, pp. 1138-1148.

[24] Gostimiroviæ, M. , Kovaè, P., Sekuliæ, M., Rodiæ, D., Pucovsky, V. "Machining Characteristics OfElectrical Discharge Machining - A Review" Journal of Production Engineering, 2016, Vol. 19.

[25] K. M. Patel \& Pulak M. Pandey \& P. Venkateswara Rao "Optimisation of process parameters for multiperformance characteristics in EDM of $\mathrm{Al} 2 \mathrm{O} 3$ ceramic composite" International Journal of Advanced Manufacturing Technology, 2010, Vol. 47, pp. 11371147.

[26] Marin Gostimirovic, Pavel Kovac, Milenko Sekulic and Branko Skoric "Influence of discharge energy on machining characteristics in EDM" Journal of Mechanical Science and Technology, 2012, Vol. 26, pp. 173-179.

[27] Joaquim Fonseca \& José Duarte Marafona “The effect of deionisation time on the electrical discharge machining performance" International Journal of Advanced Manufacturing Technology, 2014, Vol. 71, pp. 471-481.

[28] Vikasa, Apurb Kumar Roy, Kaushik Kumar "Effect and optimization of various machine process parameters on the Surface Roughness in EDM for an EN41 material using Grey-Taguchi” 3rd International Conference on Materials Processing and Characterisation, 2014, Vol. 6, pp. 383-390.

[29] Ravinder Singh Dhull and Upender Dhul "Parametric optimization of electric discharge machining of SCM415 alloy steel material using Taguchi Technique" International Journal of Research in Advent Technology, 2016, Vol. 4, pp. 88-94.

[30] Khalid Hussain Syed, Kuppan Palaniyandi "Performance of electrical discharge machining using aluminium powder suspended distilled water" Turkish J. Eng. Env. Sci., 2012, Vol. 36, pp. 195-207.

[31] Naveen Beri, S. Maheshwari, C. Sharma, Anil Kumar "Performance evaluation of powder metallurgy electrode in electrical discharge machining of AISI D2 steel using Taguchi Method" International Journal of Mechanical, Aerospace, Industrial, Mechatronic and Manufacturing Engineering, 2008, Vol. 2, pp. 225-229. 
Syed Asghar Husain Rizvi, Prem Kumar Bharti and Sanjay Agarwal

[32] Habib Sidhom, Farhat Ghanem, Tidiane Amadou, Gonzalo Gonzalez and Chedly Braham "Effect of electro discharge machining (EDM) on the AISI316L SS white layer microstructure and corrosion resistance" International Journal of Advanced Manufacturing Technology, 2013, Vol. 65, pp. 141-153.

[33] Ahsan A. Khan, Mohammed B. Ndaliman, Zakaria M. Zain, Mohammad F. Jamaludin and Umar Patthi "Surface Modification using Electric Discharge Machining (EDM) with Powder Addition" Applied Mechanics and Materials, 2012, Vols. 110-116, pp. 725733.

[34] M. K. Pradhan "Estimating the effect of process parameters on MRR, TWR and radial overcut of EDMed AISI D2 tool steel by RSM and GRA coupled with PCA" International Journal of Advanced Manufacturing Technology, 2013, Vol. 68, pp. 591-605.

[35] V. Muthukumara, N. Rajesh, R. Venkatasamy, A. Sureshbabu, N. Senthilkumar "Mathematical modeling for radial overcut on electrical discharge machining of Incoloy 800 by Response Surface Methodology" 3rd International Conference on Materials Processing and Characterisation, 2014, Vol. 6, pp. 1674-1682.

[36] Iosub Adrian; Eugen Axinte, Florin Negoescu "A Study about micro-drilling by electrical discharge method of an $\mathrm{Al} / \mathrm{SiC}$ hybrid composite" International Journal of Academic Research, 2010, Vol. 2, pp. 6-13.

[37] Hargovind Soni , T. K. Mishra and M.K.Pradhan "Multi-Response optimization of EDM parameters by Grey-PCA Method" International Journal of Current Engineering and Technology, 2013, Vol. 3, pp. 19411945.

[38] M. Boujelbene, E. Bayraktar, W. Tebni, S. Ben Salem "Influence of machining parameters on the surface integrity in electrical discharge machining" Archives of Materials Science and Engineering, 2009, Vol. 37, pp. 110-116.

[39] Anirban Bhattacharya, Ajay Batish and Naveen Kumar "Surface characterization and material migration during surface modification of die steels with silicon, graphite and tungsten powder in EDM process" Journal of Mechanical Science and Technology, 2013, Vol. 27, pp. 133-140.

[40] A.K.M. Asif Iqbal and Ahsan Ali Khan "Influence of Process Parameters on Electrical Discharge Machined Job Surface Integrity” American J. of Engineering and
Applied Sciences, 2010, Vol. 3, pp. 396-402.

[41] Jun Li, Shangyao Shi and Shiping Zhao "Modeling and Analysis of Micro-hole in Die-sinking EDM Process through Response Surface Method based on the Central Composite Design" International Journal of Signal Processing, Image Processing and PatternRecognition, 2013, Vol. 6, pp. 351-364.

[42] K.Tamil Mannan,Arkanti Krishnaiah, Siva Prasad Arikatla "Surface characterization of electric discharge machined surface of high speed steel" Advanced Materials Manufacturing \& Characterization, 2013, Vol. 3, pp. 161-168.

[43] S. Dewangan, C. K. Biswas, S. Gangopadhyay "Optimization of the quality and productivity characteristics of AISI P20 tool steel in EDM process using PCA-based grey relation analysis" 5th International \& 26th All India Manufacturing Technology, Design and Research Conference, 2014, pp. 1551-1554.

[44] Himanshu Payal, Sachin Maheshwari, Pushpendra S. Bharti "Effect of tool material on surface roughness in electrical discharge machining" Journal of Production Engineering, 2016, Vol. 9, pp. 27-30.

[45] Rajendra.M, G. Krishna Mohana Rao "Experimental evaluation of performance Of Electrical Discharge Machining of D3 Die Steel with A12O3 abrasive mixed dielectric material by using design of experiments" International Journal of Research in Engineering and Technology, 2014, Vol. 3, pp. 599-606.

[46] N. Annamalai, V. Sivaramakrishnan, B. Suresh kumar, N.Baskar "Investigation and Modeling of Electrical Discharge Machining process parameters for AISI 4340 steel" International Journal of Engineering and Technology, 2014, Vol. 5, pp. 4761-4770.

[47] Satpal Singh and C.S. Kalra "Experimental Study of PMEDM on EN 24 Steel with Tungsten Powder in Dielectric" International Journal on Emerging Technologies, 2014, Vol. 5, pp. 153-160.

[48] Mohammadreza Shabgard, Mirsadegh Seyedzavvar, Samad Nadimi Bavil Oliaei "Influence of Input Parameters on the Characteristics of the EDM Process" Journal of Mechanical Engineering, 2011, Vol. 57, pp. 689-696.

[49] G Krishna Mohana Rao, S. Satyanarayana, M Praveen "Influence of Machining Parameters on Electric Discharge Machining of Maraging Steels - An 
Experimental Investigation" Proceedings of the World Congress on Engineering, 2008, Vol. 2.

[50] Ahmet Hascalýk, Ulas Caydas "Electrical discharge machining of titanium alloy (Ti-6Al-4V)" Applied Surface Science, 2007, 253, pp. 9007-9016.

[51] Shishir Mohan Shrivastava , A.K.Sarathe "Influence of process parameters and electrode shape configuration on material removal rate, surface roughness and electrode wear in die sinking EDM: A Review" International Journal of Emerging Technology and Advanced Engineering, 2014, Vol. 4, pp. 139-145.

[52] Bhavesh A. Patel, D. S. Patel, Haresh A. Patel "Influence of Electrode Material and Process Parameters on Surface Quality and MRR in EDM of AISI H13 using ANN" International Journal on Recent and Innovation Trends in Computing and Communication, 2013, Vo. 1, pp. 858-869.

[53] Reza Teimouri and Hamid Baseri "Study of Tool Wear and Overcut in EDM Process with Rotary Tool and Magnetic Field" Advances in Tribology, 2012, pp. 18.

[54] Amoljit S. Gill, Sanjeev Kumar "Surface Roughness Evaluation for EDM of EN31 with Cu-Cr-Ni Powder Metallurgy Tool” International Journal of Mechanical, Aerospace, Industrial, Mechatronic and Manufacturing Engineering, 2014, Vol. 7, pp. 1304-1309.

[55] S. Ben Salem, W. Tebni , E. Bayraktar "Prediction of surface roughness by experimental design methodology in Electrical Discharge Machining (EDM)" Journal of Achievements in Materials and Manufacturing Engineering, 2011, Vol. 49, pp. 150-157.

[56] Deepu P.Nair, Dr. Binu C.Yeldose, Dr. Cibu K. Varghese "Investigation of Surface Roughness on M300 Steel Machined By EDM" International Journal of Engineering and Innovative Technology, 2014, Vol. 4, pp. 91-94.

[57] Gurtej Singh, Paramjit Singh, Gaurav Tejpal, Baljinder Singh "Effect Of Machining Parameters On Surface Roughness Of H13 Steel In EDM Process Using Powder Mixed Fluid" International Journal of Advanced Engineering Research and Studies, 2012, Vol. 2, pp. 148-150.
[58] V. Chandrasekaran, D. Kanagarajan, R. Karthikeyan "Optimization of EDM Characteristics of WC/5ni Composites Using Response Surface Methodology" International Journal of Recent Technology and Engineering, 2013, Vol. 2, pp. 108-115.

[59] Rajesha S, C.S. Jawalkar, Radha Raman Mishra, A.K. Sharma, Pradeep Kumar "Study of recast layers and surface roughness on Al-7075 metal matrix composite during EDM machining" International Journal of Recent advances in Mechanical Engineering, 2014, Vol. 3, pp. 53-62.

[60] Harpuneet Singh "Investigating the Effect of Copper Chromium and Aluminum Electrodes on EN-31 Die Steel on Electric Discharge Machine Using Positive Polarity" Proceedings of the World Congress on Engineering, 2012, Vol. 3.

[61] Syed Asghar Husain Rizvi, Sanjay Agarwal "An investigation on surface integrity in EDM process with a copper tungsten electrode" 18th CIRP Conference on Electro Physical and Chemical Machining, 2016, Vol. 42, pp. 612-617.

[62] Mayank Srivastava, Syed Asghar Husain Rizvi "Analysis of the influence of parameters of EDM of EN-24 for Material Removal Rate and Tool Wear Rate" International Journal of Innovative Research in Science, Engineering and Technology, 2017, VVol. 6, pp. 108113.

[63] Deepika Mishra, Syed Asghar Husain Rizvi, Mohd. Ziaulhaq "Experimental Investigation of EDM of AISI 4340 for Surface Integrity" International Journal of Innovative Research in Science, Engineering and Technology, 2017, Vol. 6, pp. 133-136.

[64] Deepika Mishra, Syed Asghar Husain Rizvi "Influence Of EDM Parameters On MRR, TWR And Surface Integrity Of AISI 4340”, International Journal of Technical Research and Applications, 2017, Special issue -42, pp. 163-169.

[65] Durgesh Verma, Mohd. Faizan Hasan, Syed Asghar Husain Rizvi "Parametric Optimization of Performance of EDM on Alloy Steel AISI 4147 using Taguchi Approach", Journal of Recent Activities in Production, 2016, Vol. 1, pp. 1-14. 
Syed Asghar Husain Rizvi, Prem Kumar Bharti and Sanjay Agarwal

[66] Ahmed A. Elkaseer, Samuel Bigot, Anthony Surleraux, Andrzej Rosochowski "Effect of material microstructure on the micro-EDM process", Proceedings of the 8th International Conference on Micro Manufacturing, 2003, pp. 336-342.

[67] P. Pecas, E. Henriques "Influence of silicon powdermixed dielectric on conventional electrical discharge machining", International Journal of Machine Tools \& Manufacture, 2004, Vol. 43, pp. 1465-1471.

[68] Paulo Peças \& Elsa Henriques "Effect of the powder concentration and dielectric flow in the surface morphology in electrical discharge machining with powder-mixed dielectric (PMD-EDM)", International Journal Advance Manufacturing Technology, 2008, Vol. 37, pp. 1120-1132.

[69] Gostimiroviæ, M., Kovaè, P., Sekuliæ, M., Savkoviæ, B "A study of discharge pulse energy in Electrical Discharge Machining", Journal of Production Engineering, 2011, Vol. 15, pp. 7-10.

[70] José Duarte Marafona "Black layer characterisation and electrode wear ratio in electrical discharge machining (EDM)", Journal of Materials Processing Technology, 2007, Vol. 184, pp. 27-31.

[71] Pushpendra S. Bharti, S. Maheshwari, M.K. Satyarthi "Black Layer Characterization in Electric Discharge Machining of Inconel 718", Vth International Symposium on "Fusion of Science \& Technology, 2016, 214-217.

[72] Lihua He, Jianwu Yu, Wen Duan, Zhikang Liu, Shaohui Yin, Hong Luo "Copper-tungsten electrode wear process and carbon layer characterization in electrical discharge machining", International
Journal of Advanced Manufacturing Technology, 2016, Vol. 85, pp. 1759-1768.

[73] Sanjeev Kumar, Rupinder Singh, Ajay Batish, T.P. Singh "Study the effect of black layer on electrode wear ratio in powder mixed electric discharge machining of titanium alloys", International Journal of Machining and Machinability of Materials, 2016, Vol.18, pp. 18-25.

[74] Philipp Steuera, Andreas Rebschläger, Olivier Weber, Dirk Bähre "The heat-affected zone in EDM and its influence on a following PECM process, 2nd CIRP Conference on Surface Integrity, 2014, pp. 276-28.

[75] F. L. Amorim, W. L. Weingaertner, "Influence of duty factor on the die-sinking Electrical Discharge Machining of high-strength aluminum alloy under rough machining”, Journal of the Brazilian Society of Mechanical Sciences, 2002, Vol. 24, pp. 194-199.

[76] Norliana Mohd Abbas, Darius G. Solomon "Pugh Method: Selection of Dielectric in Machining Tungsten Carbide with Electrical Discharge Machining (EDM)", International Conference on Trends in Mechanical and Industrial Engineering, 2011, pp. 204-207.

[77] S.SyathAbuthakeer, S.Mohith Kaameswaran, K.Venkatachalam, M.Vishhnuram, "Influence of process parameters in EDM machining of Aluminium Titanium Carbide Composite", International Journal of Recent Engineering Research and Development, 2017, Vol. 2, pp. 64-72.

[78] Amitabh Ghosh and Asok Kumar Mallik,2004 Manufacturing Science, New Delhi, East-West Press. 
